\title{
HIPPOCAMPAL EEG AND BEHAVIOUR IN DOG. I. HIPPOCAMPAL EEG CORRELATES OF GROSS MOTOR BEHAVIOUR ${ }^{1}$
}

\author{
D E A T ARNOLDS, F.H LOPES DA SILVA ${ }^{2}$, J W AITINK and A KAMP \\ Brain Research Depariment, Institute of Medical Physics TNO. National Health Research Organization. Itrecht \\ (The Netherlands)
}

(Accepted for publication September 14, 1978)

Under various curcumstances the hippocampal EEG shows a highly synchronized large amplitude potential variation, with a peak frequency between 4 and $7 \mathrm{c} / \mathrm{sec}$ in the dog, which is often referred to as the hippocampal theta rhythm or the rhythmic slow activity (RSA) of the hippocampus. This is an easily measurable physiological parameter that stands in close relation to the electrical processes at a cellular level (Fujita and Sato 1964; Fujita 1975) and thus, presumably, to the functioning of the hippocampus. A good deal of the hippocampal research has therefore concentrated on studying correlates between hippocampal EEG and behaviour in a variety of species (most prominently rat, cat and rabbit), in an effort to clarify the functional importance of the hippocampus.

The results of these studies have been interpreted as showing a relationship between 'the occurrence of RSA' and information processing (Klemm and Douglas 1974), various aspects of learning (Elazar and Adey 1967; Gray 1972; Landfield et al. 1972), arousal and attention (Green and Arduinı 1954; Kemp and Kaada 1975; Lindsley and Wlson 1975) and 'voluntary' movement (Vander-

\footnotetext{
The investigations were supported (in part) by the Foundation for Medical Research FUNGO, which is subsidized by the Netherlands Organısation for the Advancement of Pure Research ( $\mathrm{Z}$ W.O )

${ }^{2}$ Reprint requests to $F \mathrm{H}$ Lopes da Silva, Institute of Medical Physics TNO, 45 Da Costakade, Utrecht, The Netherlands
}

wolf et al. 1973), whlle our group has put in evidence that increases in frequency of RSA occur when a dog switches from one behavloural act to another, within a behavioural mode characterized by movement (Lopes da Silva and Kamp 1969, Kamp et al. 1971; Arnolds et al. 1975). To our mind 3 factors are of primary importance in perpetuating the disagreement concerning the behavioural correlates of the hippocampal EEG.

(a) The EEG is not, or rudimentarily, quant1fled in most studies. Thus 'theta was present' may mean quite different things in two different studies.

(b) The behaviour is described on different levels of complexity in different studies. The behaviour in a discrimination learning situation might by one experimenter be described as 'the animal learns', by the other as 'the animal approaches a goal', and by yet another as 'the anımal walks'. Again lack of quantification of the actually observed behaviour makes it difficult to compare and integrate results.

(c) A third factor that may be the cause of considerable confusion is possibly the frequent use of bipolar hippocampal derivations, especially in cats and rats (e.g., Grastyán et al. 1959; Vanderwolf 1969). To appreciate this point it should be realized that the RSA component of the hippocampal EEG is highly coherent throughout large extents of the hippocampal formation (Holsheimer and Feenstra 1977). Therefore the electrode placements are not very critical provided the deri- 
vation uses a reference far from the hippocampal formation.

On the other hand, however, gradual phase reversals have been observed within the hippocampus (Winson 1976). Thus the amplitude of a signal recorded from bipolar electrodes will be highly dependent on the phase relationship between the potential fluctuations at the tips of the two electrodes. If shifts were to occur in this phase relationship - and this possibility cannot at present be excluded the amplitude measured between bipolar electrodes might be difficult to interpret. This is the more crucial since amplitude is the spectral parameter that seems to play the most important role in the decision about the 'presence' or 'absence' of RSA on visual inspection of an EEG record.

In this study we have therefore used common reference derivations and we have quantıfied both the EEG and behaviour along the same time scale. Using a system of computer analysis we were able to establish statistically significant correlations between events in the behavioural and EEG domains. This analysis system has been described extensively in a previous publication (Arnolds and Lopes da Silva 1977).

In an introductory experiment we made an inventory of the motor behaviours correlated with upward shifts in amplitude or frequency in the theta band of the hippocampal EEG in the dog. Next we investigated some of the correlates suggested by this survey in more detail. The experiments involved the intensive study of a small number of dogs over an extended period of time.

\section{Material and methods}

\section{(1) Electrodes and their placement}

Under anaesthesia 4 dogs were prepared with bundles of 3 or 4 intertwined wires (100 $\mu \mathrm{m}$ diameter) insulated to 0.5 or $1 \mathrm{~mm}$ from the tip, with intertip distances of 0.5 or $2 \mathrm{~mm}$. The bundles were implanted according to standard stereotaxic techniques in a variety of brain structures, including the hippocampus. The stereotaxic coordinates were based on the atlases of the dog's brain of Lim et al. (1960) and Adrianov and Mering (1959). The coordinates were adapted to the German Boxer on the basis of our past experience of the brains of these dogs (Storm van Leeuwen et al. 1967). The tips of the hippocampal electrodes selected for analysis were shown by post mortem histological examination to be located in, or in close proximity to, the hippocampal formation (Fig. 1). The ends of the electrodes were soldered to a connector plug which was fixed to the dog's skull with dental cement.

\section{(2) Recording}

In the first experiment the dog could move about freely in a room of approximately $48 \mathrm{~m}^{2}$. In subsequent experiments the animal was strapped into a classical treadmill; in this set-up it could walk around over ground in circles of $2.60 \mathrm{~m}$ diameter. This arrangement allowed the displacement and hence the speed of walking to be measured. The resolving power of the displacement transducer was $3.4^{\circ}$ which is equivalent to a displacement of $8 \mathrm{~cm}$. In these experiments the dog usually carried a small accelerometer on its back and head which was used as a movement transducer. In some cases it also had a light cell on its head in order to measure the displacement of the head in relation to a fixed light source. Usually the EMG of one of the forepaws was recorded. In some cases the EMG of a neck muscle was recorded as well. These signals served as direct indicators of aspects of the dog's motor behaviour. Furthermore, the behaviour of the animal could be monitored by means of a closed circuit T.V. system and was scored in a digital code by two observers. The EEG derivations were to one common electrode, a stainless steel pin placed in the frontal bone at the level of the frontal sinus. Signals indicative of behaviour as well as the EEG signals of interest were transmitted by means of a 16-channel radiotelemetry system (Storm van Leeuwen and Kamp 1969). The 

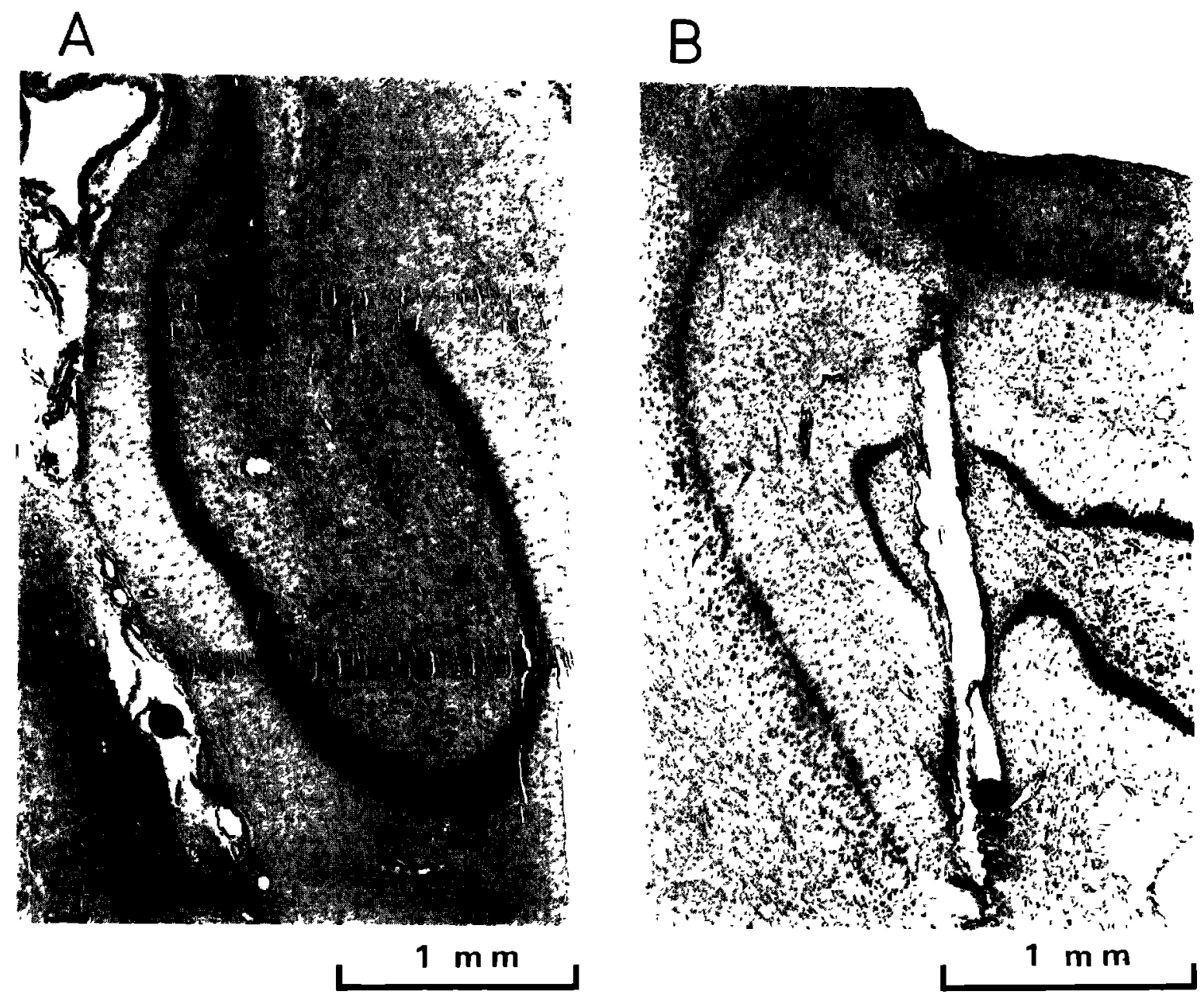

Fig. 1. Electrode positions (given by the black dots) in the dogs of which EEG records are shown in this paper A an electrode position in the ventral hippocampus Derivations from this electrode were used for the analysis llustrated in Fig. 4. B a position in the dorsal hippocampus Derivations from this location were used for the EEGs shown in Figs. 5, 7 and 9

signals were further amplified by a 16-channel EEG machine (Offner R-type dynograph or Elema). The EEG signals, the signals indicating behavioural aspects, the behavioural code, a signal indicating the moment at which the dog obtained a reward and a digital time code were stored on a multichannel analogue tape recorder (EMI) and written out on paper.

(3) Data acquisition and computer preprocessing (see Fig. 2)

3.1. EEG. The hippocampal EEG was sub- mitted to spectral analysis by means of a series of 18 filters having a bandwidth of $1 \mathrm{~Hz}$ in the range from 2 to $11 \mathrm{~Hz}$ and of $2 \mathrm{~Hz}$ from 12 to $26 \mathrm{~Hz}$, as described in detail by Lopes da Silva and Kamp (1969).

At each sample request the rectified and smoothed output of the filters was scanned by an analog-digital converter so that the instantaneous spectral content of the EEG signal was registered in the computer as a set of numbers (to be called a spectral sample), representing the amplitudes of all filters. Sam- 


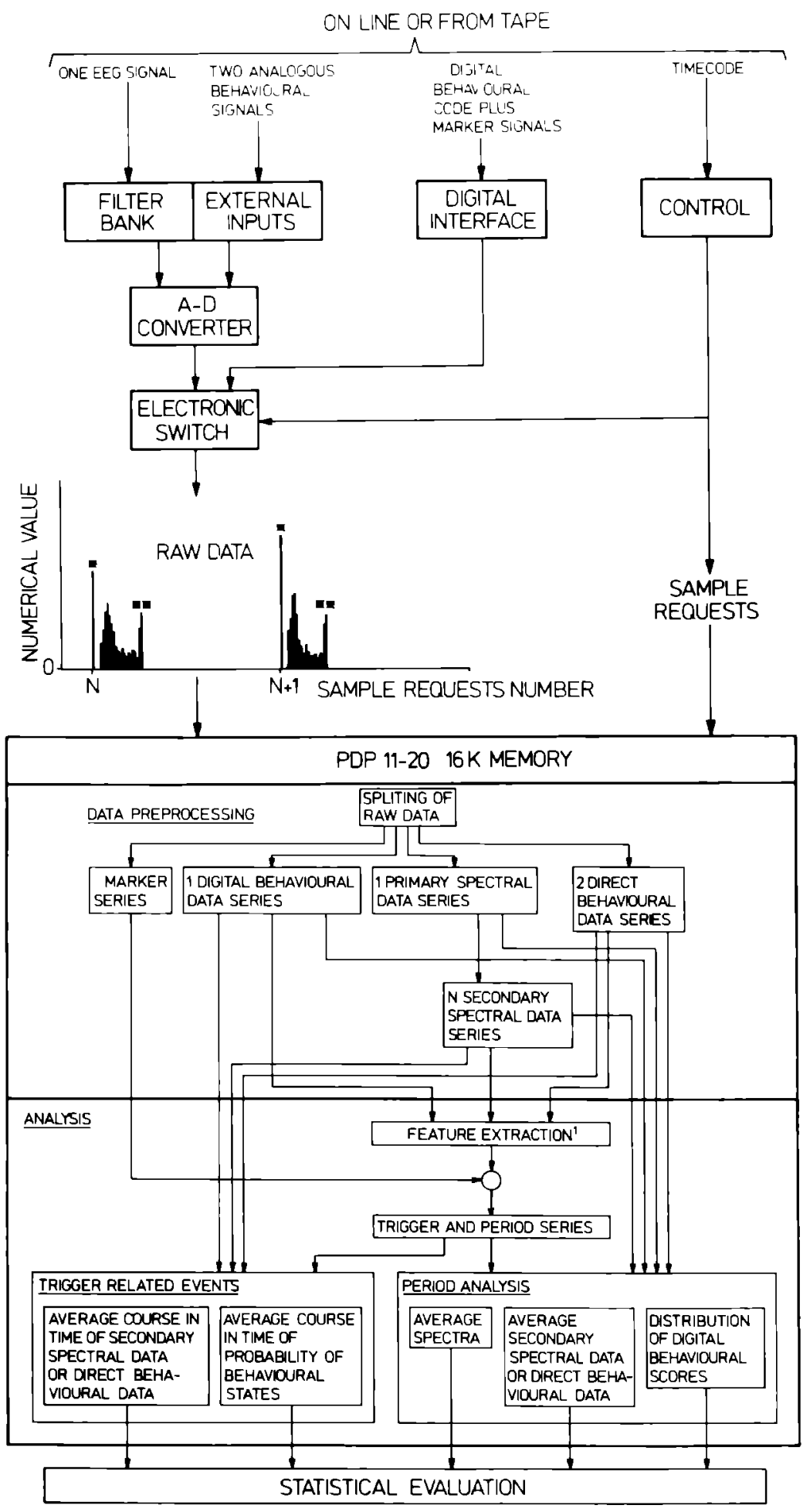

Fig 2. Flowchart of the data processing in the analysis system, including a graphical representation of the data as they reach the computer Synchrony in the sampling of the analogous and the digital signals is achieved by means of an electronic switch which at each sample request first opens a gate so that the behavioural and marker information may enter the computer and then switches to the AD converter to let an EEG spectrum plus simultaneous 'direct' behavioural data be registered The second part of the figure gives a flowchart of the data processing possible in the computer 1 , feature extraction could also be done 'by hand' from the written record since the sample requests were generated in synchrony with the tıme code which was registered on paper as well as on tape. (From Arnolds and Lopes da Silva 1977 ) 
ple requests were generated every $200 \mathrm{msec}$ and locked with the time code. The resulting series of spectral samples was called the pr1-
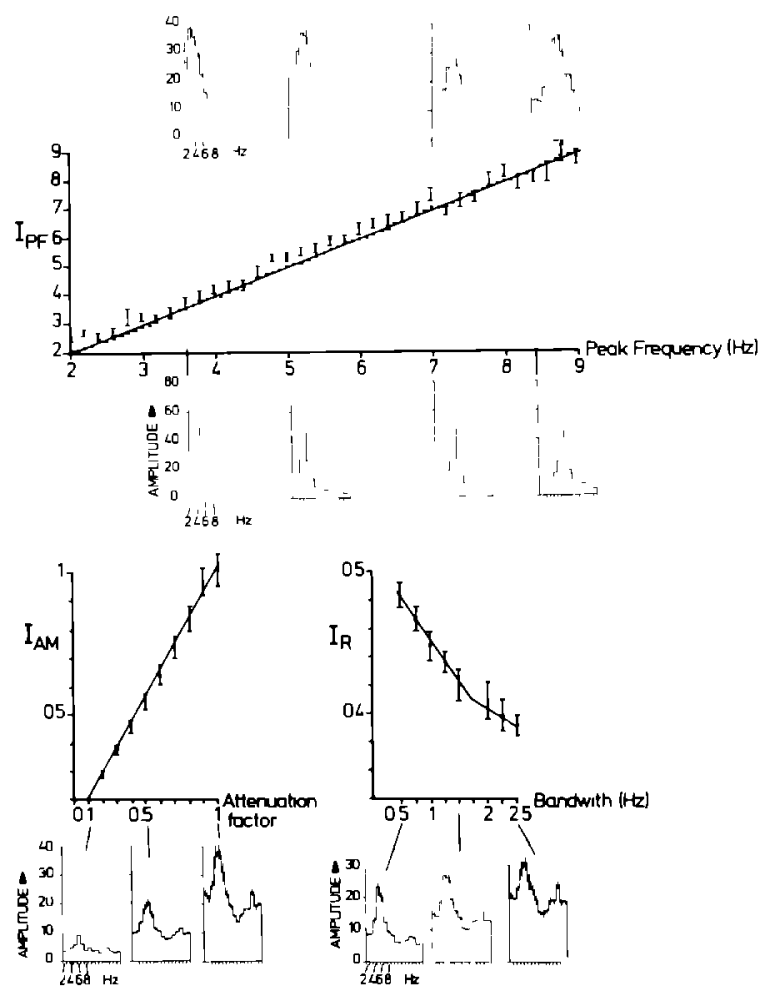

Fig 3. Representative calıbration curves for each of the spectral parameters used throughout this paper The upper curve shows the relationship between $I_{P F}$ and the frequency of a pure sine wave used as an input to the analysis system. The frequency of the input signal was increased in steps of $0.1 \mathrm{~Hz}$ The $I_{P F}$ values found in this calibration are indicated by simple dots. The 4 histograms at the base of the figure show spectra of the sine wave signal used in this calibration In the same frame the relationship is shown between $I_{P F}$ and the centre frequency of bandpass filtered ( $24 \mathrm{~dB} /$ octave, bandwidth $2 \mathrm{~Hz}$ ) white noise The centre frequency was shifted in steps of $02 \mathrm{~Hz}$ Each calıbration point was obtained by averaging 18 values. The standard error of the mean is indicated. The spectral analysis of some of the calıbraiion signals is shown in the 4 histograms above the curve. In order to calıbrate $I_{A M}$ the same recording of a simulated EEG signal was registered in the computer at different amplitudes, using a linear attenuation network $I_{R}$ was calibrated using simulated EEG sıgnals with different bandwidths For each point of the $I_{A M}$ and $I_{R}$ curve 10 values were averaged Again a few spectra are shown of the calıbration signals used mary spectral data series. Reduction of these primary data was acheved hy deriving a number of so-called secondary spectral data series. In such a secondary series each spectral sample was represented by a single number characterising one aspect of the spectrum.

Three indices were derived from each recorded spectrum. $I_{P F}$ was designed to give an indication of the peak frequency of the spectrum, $\mathrm{I}_{\mathrm{AM}}$ gave an indication of the amplitude of the spectral components in a $3 \mathrm{~Hz}$ wide band around the peak frequency, while $I_{R}$ was designed to give a measure of the rhythmicity of the signal as it would appear on visual inspection (see Appendix). Representative calibration curves of these spectral indices are shown in Fig. 3.

3 2. Behavioural signals. Two types of signal were registered: (a) 'direct' physical or physiological measurements such as a signal derived from the treadmill indicating the dog's displacement, or an integrated EMG sıgnal. These signals were analogous variables and were sampled every $200 \mathrm{msec}$ in the same way as the EEG spectral data. Durng the preprocessing, spectral samples and 'direct' behavioural data were separated. (b) Descriptive behavioural elements. In the dog's behaviour we distinguished 2 mutually exclusive classes: gross motor behaviour and head position. In each of these classes a number of different behavıoural categories was defıned (again so as to be mutually exclusive). The behavioural categories within the class of gross motor behaviour were- lying down, sitting, standing, walking, turning. Within the class 'head position' we distinguished: head in line with body axis (neutral), head up, down, left, right and in food dish. Each observer scored the behavioural categories within one behavioural class. Each possible behavioural state (combination of a head position and a gross motor category) was characterssed by a specific digital electrical signal. These signals were preprocessed so that the behavioural information formed a data series consisting of one number per sample request; a different number for each possible behavioural state. 
Also a series of sample request numbers indicating the moments at which the dog obtained a reward was registered in the computer.

In summary, at the end of the phase of data acquisition and preprocessing a number of data series (spectra, secondary spectral data, 'direct' and digital behavioural data) were available which were precisely sample-tosample related in time; a series of numbers indicating the moment at which the dog was rewarded was also available.

\section{(4) Analysis (see Fig. 2)}

4 1. Period analysis. In a digital behavioural data series the sample numbers were determined which indicated the beginning and the end of the period during which these data fulfilled a certain condition. Such a period series would for example cover all the periods in an experiment during which the dog was scored to be walking At request, EEG spectra, the value of secondary spectral parameters and of 'durect' behavioural parameters occurring within the periods so defıned, were averaged and submitted to statistical analysis.

42 Event-related analysis. In a behavioural data series the sample numbers were determined at which a specific event occurred, such as the transition from one behavioural state to another. The series of sample numbers so obtained was called a trigger series. Using such a trigger series it was possible to compute the average time course of a secondary spectral variable or a 'durect' behavioural variable within a time interval of a few seconds before and after the trigger event.

Whether a change in such a variable occurring in association with a certain trigger was significant, was assessed statistically. In a similar way it was possible to compute the probability of occurrence of various digital behavioural categories and states as a function of time, in relation to a certain trigger event. The estimate of the probability of occurrence of a behavioural category is binomially distributed so that confidence limits could be assigned to each average value and thus the significance of variations in these averages could be easily assessed. Each of the analyses shown is the result of averaging a number of behavioural events during which the behaviour was similar both with respect to its outward morphology and to the experimental circumstances under which it occurred. All averaged events for a single analysis were chosen at random from a single experiment.

In the statistical treatment of the data we used non-parametric tests, primarily because the distribution of the data (e.g., secondary spectral parameters) was not precisely known. Moreover, in most cases the question of interest was whether the difference between the values of one variable at two moments in time $\left(t_{-n}\right.$, at $n$ samples before a certain trigger and $t_{m}, m$ samples thereafter) differed significantly from zero or not. It was commonly found that a significant difference between the values measured at $t_{-n}$ and $t_{m}$ over $N$ trials, as tested by the sign test, could be established, even though the standard errors of the corresponding mean values might overlap (see, e.g., Fig. 7, 'velocity'). This is due to the trivial fact that the sign test is indépendent of variations in mean values.

In the graphical presentation of the eventrelated analyses of spectral and durect behavloural parameters (Figs. 4, 6, 7 and 9) we used the following conventions: the arrow ind1cates the trigger event; the bar through each data point indicates the standard error of the mean. $\mathrm{N}$ indicates the number of averaged events. Where a curve is thickened there exists a statistically significant difference between that part of the curve and the value indicated by an asterisk chosen as a reference (sign test). The thicker the line the more significant the statistics. In any case $P$ is $<0.05$. The greatest thickness indicates $P<0.001$. When histograms are presented with such an eventrelated analysis, they represent the running spectral analysis of a number of $200 \mathrm{msec}$ tıme bins around the trigger event. The placement of the spectra corresponds to the time scale of the curves. The dash through the top of each histogram column (1n some cases the 
line width of the top of the bar) indicates the standard error. Where no such indication is visible, the standard error was too small to be indicated in relation to the line width used for drawing. $\triangle$ indicates arbitrary units.

\section{Results}

\section{(1) Behaviour correlated with spectral shift}

Procedures. In this experiment we aimed to get a general impression of the motor behaviour of the solitary dog correlated with a range of spectral features of the hippocampal EEG.

To this end a dog was left enturely free to show which ever behaviour was possible in that situation, for a period of $1000 \mathrm{sec}$. The hippocampal EEG was subjected to on-line, real time frequency analysis. A hardware logic circult detected the moments at which the $5 \mathrm{c} / \mathrm{sec}$ component of the signal remained below and the $6 \mathrm{c} / \mathrm{sec}$ component stayed above a certain pre-set level for a period of more than $200 \mathrm{msec}$. This procedure allowed the detection of upward shifts in amplitude or frequency in the theta range of the hippocampal EEG. These events wll henceforth be referred to as spectral shifts. Each time a spectral shift was detected the dog obtained a food reward from a food dispenser which gave a clearly audible click. Thus information on the EEG spectrum was fed back to the dog. In the course of a series of shaping experiments the dog was required to produce increasingly more distinct spectral shifts since the amplitude level required for reward was gradually changed. A series of control experiments was also performed to test for the behavioural effect of rewarding spectral shifts. In these experiments the dog was rewarded at random at a rate of 80 rewards $/ 1000 \mathrm{sec}$; hence the reward was not longer linked to the production of spectral shifts.

Results. The overall behavioural result of rewarding spectral shifts (feedback experiments) was an animal showing a variety of motor behaviour consisting in modulations in walking such as changing walking speed, starting to walk, stopping, changing direction etc. as well as brisk head movements of varied form, often produced near the food dish and in conjunction with eating, or in conjunction with turning. At the same time the dog produced an average of 80 spectral shifts/1000

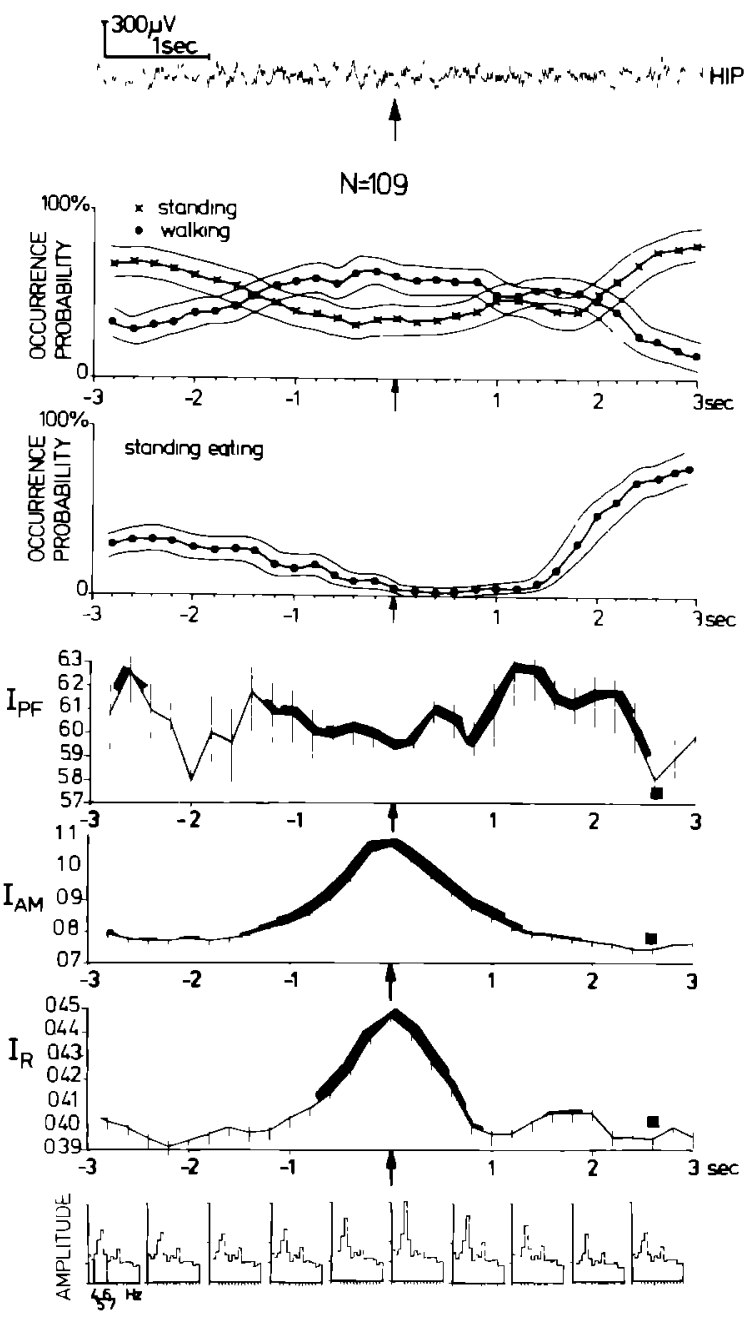

Fig 4. Upper part: hippocampal EEG during a single spectral shift The next 2 frames frequency with which 3 behavioural categories were scored as a function of time $95 \%$ confidence limits are indicated. Next 3 curves average values of $I_{P F}, I_{A M}$ and $I_{R}$ as a function of time in relation to the moment at which the spectral shift was detected. Note that the spectral shifts which led to reward of the dog are characterlzed by an increase in frequency, amplitude and rhythmicity indices 
sec recording session over the last 14 sessions. The range was broad, however (48-147/1000 sec). Fig. 4 shows the average morphology of the spectral shifts that the dog produced during one entire $1000 \mathrm{sec}$ experimental session. An analysis of the gross motor behavlour scored with this population of spectral shifts showed a significant increase in the probability that the dog was walkıng in relation to the moment at which the spectral shift was detected, while the probability of standing decreased $(P<0.05$, binomial distribution). This result affirms quantitatively the correlation between transitions from standing to walking and the occurrence of spectral shifts. Abolishing the contingency between reward and spectral shift in control experiments caused the number of spectral shifts per recording session to dwindle to zero within 5 sessions. We compared a 'feedback' and a control experiment regarding the average amount of time spent by the dog in a number of behavioural states during 18 periods, each with a duration of $50 \mathrm{sec}$. In both experiments the dog received the same number of rewards. It emerged that the dog 'walked with head neutral' signuficantly more $(P<0.001$ Wllcoxon test) during the 'feedback' experiment and 'stood still with head neutral' significantly less $(P<0.01)$. There was no significant difference between the amounts of time spent 'standing while eating'. During the control experiments the dog would lie down more often but the difference was statistically small $(P<0.075)$. Thus the overall behaviour of the dog changed signuficantly when the contingency between spectral shift and reward was abolished. We also had the impression that the behaviour became gradually less vigorous and brisk as the control experiments went on. In further experiments in another dog we succeeded in bringing the production of spectral shifts under the control of a conditioned stimulus (CS), a 4 sec buzzer sound. In relation to the onset of the CS the dog showed a transition either from lying down to standing (to walking) or from sitting to standing (to walking) or from standing to walking.
These transitions were often accompanied by a vigorous head movement. In all cases these behavioural transitions were correlated with a spectral shift. In about $40 \%$ of the trials the a priori set criteria for the detection of spectral shifts were met, and thus reward was given.

These results supported the hypothesis that in the dog spectral shifts are correlated with increases in motor activity, that decreases in motor activity would go along with decreases in amplitude and frequency of the hippocampal EEG and that the magnitude of these spectral modulations would be correlated with the vigour of the motor behavioural change. Therefore we investigated in the next experiments the EEG correlate of various more precisely defined modulations in motor behaviour, in most cases using conditioning procedures to shape the behaviour so that the acts of interest would occur at a high frequency and with a reasonably stable morphology. We also derived direct behavioural signals (EMGs, accelerometers) and measured the dog's displacement in the classical treadmull in order to obtain better time relationships between EEG phenomena and behaviour.

\section{(2) Modulations in gross motor behaviour}

Procedures. The dog learned to come to a halt at about $1 \mathrm{~m}$ from the food dish after having walked a tour in the treadmill once. There it had to remain, standing almost motionless for a period of $5-15 \mathrm{sec}$ (the length of this period was varied at random). If this sequence had been performed with sufficient precision according to the judgement of the experimenter, the dog was rewarded; it walked the short distance still separating it from the food dish, ate and then started on its next round.

To get an impression of the effect of modulations within the walking mode we repeated this experiment in a slightly modified version. We activated the food dispenser during some randomly picked trials while the dog was walking. This caused it to speed up in order to collect the unexpected reward. 


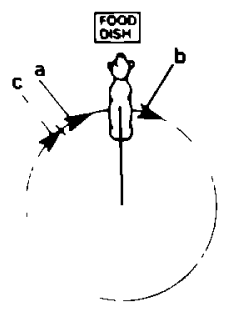

$a=A F T E R$ A PERIOD OF IMMOBILITY THE DOG IS REWARDED WALKS TO FOOD DISH AND EATS $b=D O G$ START WALKING AFTER HAVINC EATEN

$c=D O G$ STOPS ATT A DISTANCE OF ABOUT ONE METER FROM FOOD DISH
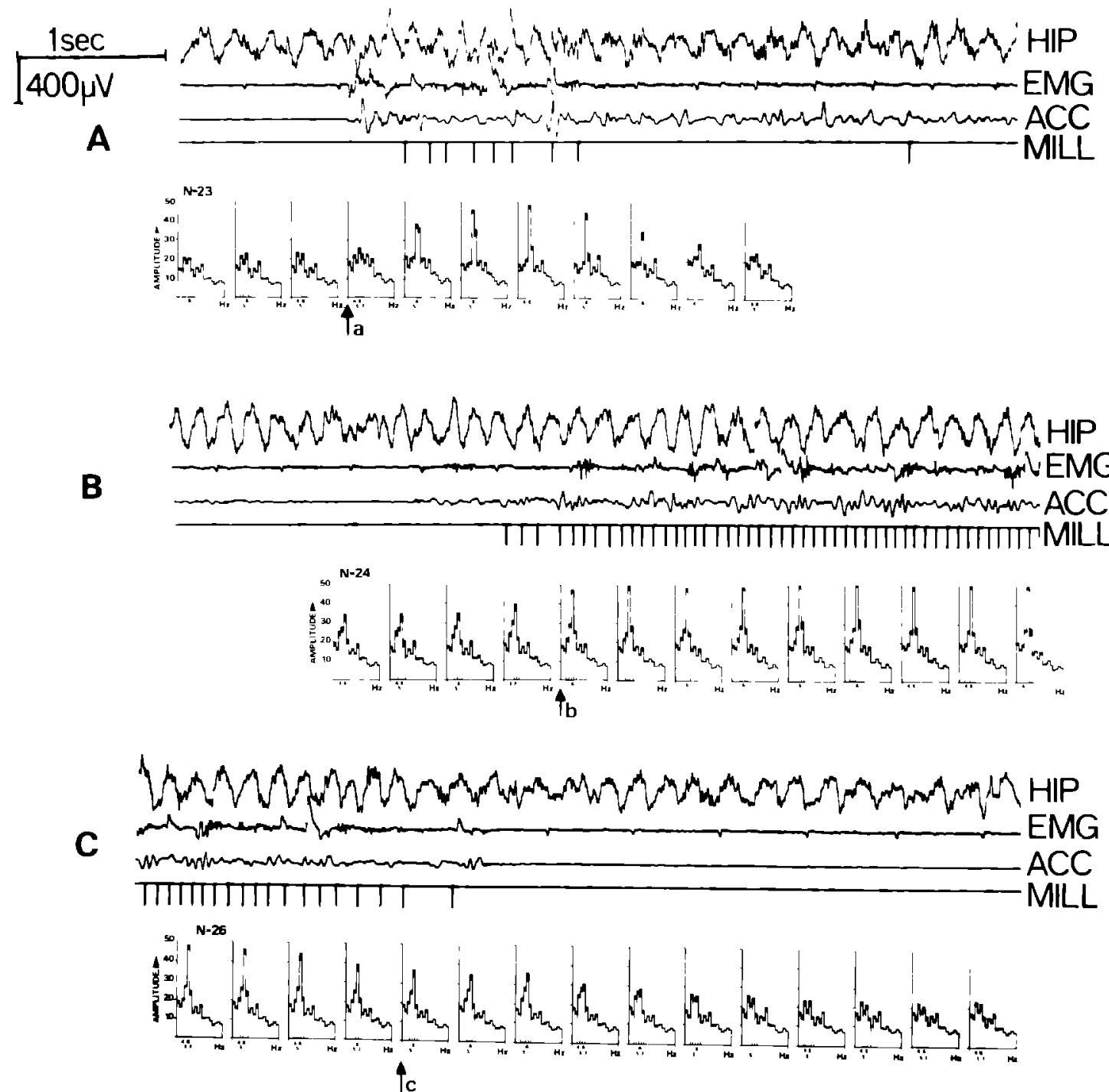

Fig. 5. The heading of this figure gives a synopsis of the experimental situation and indicates the trigger points used in analysis The curves under $\mathrm{A}, \mathrm{B}$ and $\mathrm{C}$ show the relevant parts of a single 'typical trial' HIP, hippocampal EEG, EMG, EMG of the shoulder muscles of one of the forepaws; ACC, output of the movement transducer on the dog's back; MILL, output of the speed transducer on the treadmill (the higher the pulse density, the higher the speed) For a statistical analysıs of this experiment see Fig. 6 


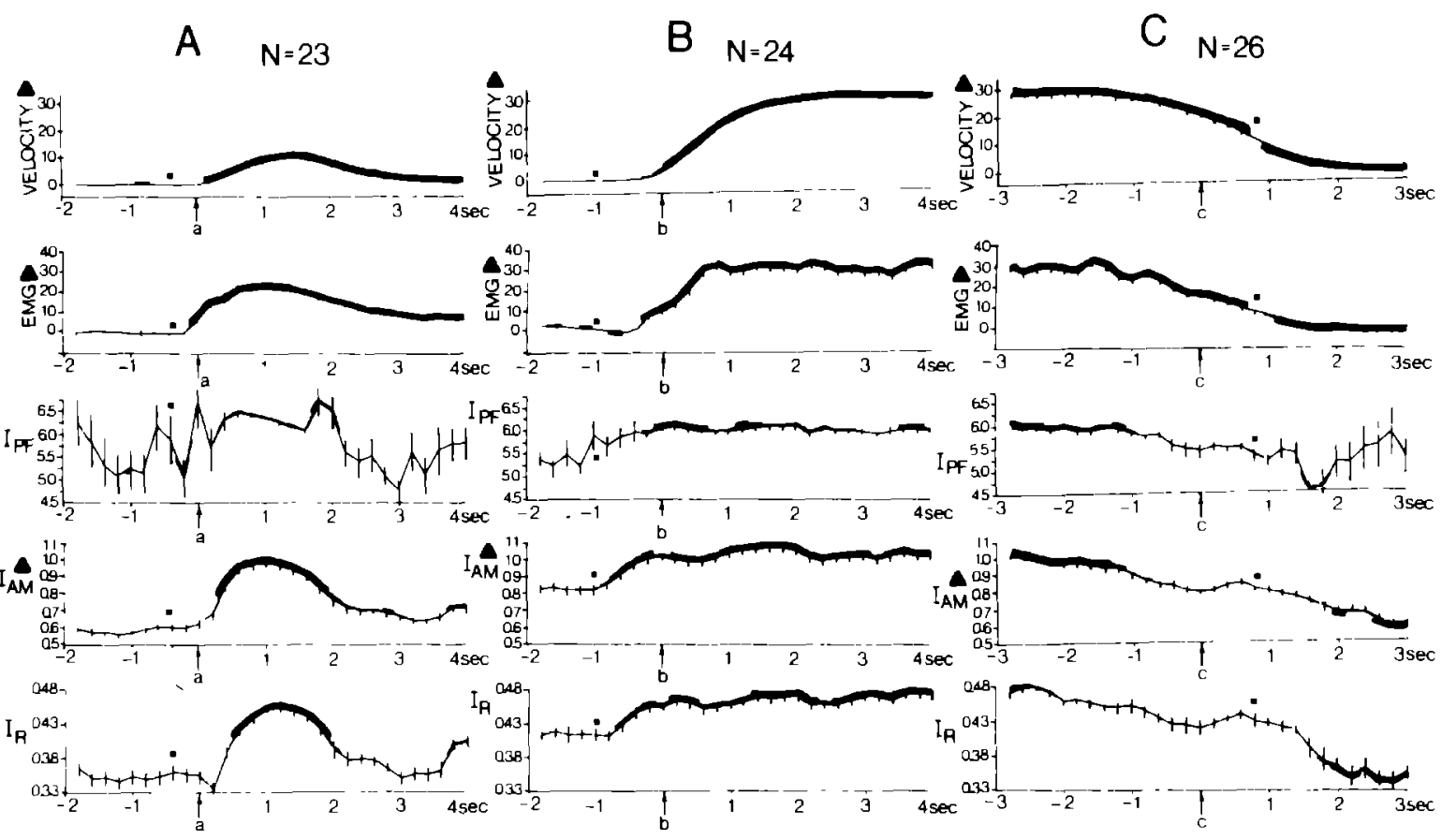

Fig 6. Column A average values of the walking speed (integrated treadmill output), smoothed and rectıfied forepaw EMG, $I_{P F}, I_{A M}$ and $I_{R}$ are shown as a function of time in relation to the moment the dog is rewarded (a) (see also $F_{1 g} 5$ ) Column $B$ same type of analysis of EEG and behavioural parameters in relation to the moment the dog starts walking after it has finished eating (b) Column C analysis of the EEG and behavioural parameters related to the moment the dog stops walking (c)

Results The spectral parameters have been analysed in relation to the moment the dog received the reward, and hence walked to the food dish, the moment it started walking after having eaten, the moment it stopped (Figs. 5 and 6), and with respect to the moment the animal received an unexpected reward while walking (F1g. 7).

From this analysis the following is clear: (a) transition from walking to standing (c in Figs. 5 and 6) is correlated with a decrease in both frequency and amplitude and with a decrease in apparent rhythmicity of the signal; (b) it is confirmed that a transition from standing to walking (a, b in Figs. 4 and 5) goes along with an increase in frequency and amplitude and an increase in rhythmicity; (c) the behavioural state of walking is correlated with large amplitude, high frequency RSA, with a clear apparent rhythmicity; (d) the behavioural state of standing is correlated with small amplitude, low frequency RSA, of a lower rhythmicity; (e) the unexpected presentation of a reward and the concomitant increase in motor activity (1.e. the speed with which the animal walks (Fig. 7)) is correlated with an increase in frequency in the theta band while there is a transient decrease in rhythmicity and a transient increase in amplitude.

The behavioural state of 'standing while eating' appears to be correlated with a hippocampal EEG that differs significantly from both 'standing stıll' and 'walking', as illustrated by the following analysis.

For 76 independent periods of 'walking', 53 of 'standing still' and 39 of 'standingwhile-eating' the average $I_{P F}, I_{A M}$ and $I_{R}$ have been computed. The average duration of the 'walking' periods was $6 \mathrm{sec}$, of the 'standing' periods $10.6 \mathrm{sec}$ and of the eating periods $1.8 \mathrm{sec}$. It emcrged that the average values of 

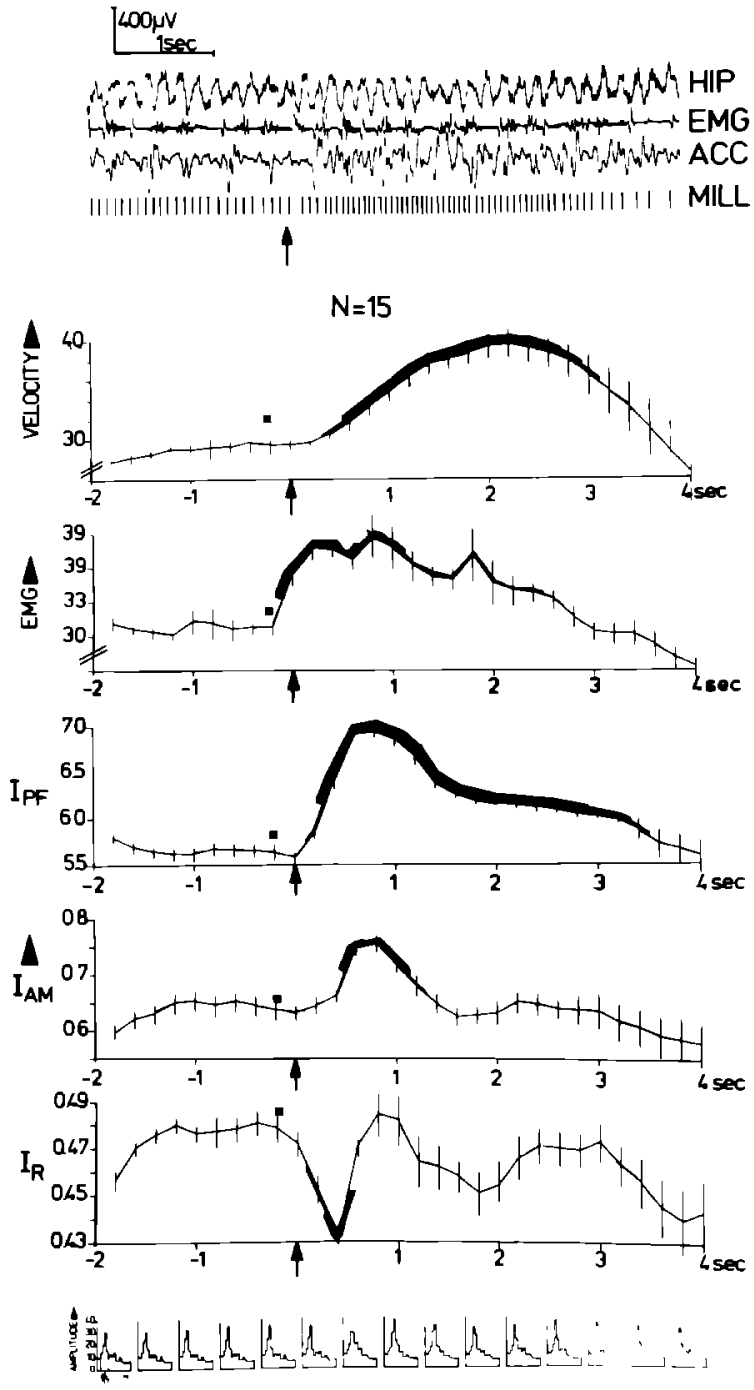

Fig 7 Upper part hippocampal EEG (HIP), EMG of a forepaw muscle (EMG), output of the movement transducer on the dog's back (ACC) and output of the speed transducer on the treadmill (MILL) for a typical increase in walking speed, due to reward while the dog is walking, for a single trial. Next 5 curves average values of the walking speed (integrated treadmill output), smoothed and rectified forepaw EMG, $I_{P F}, I_{A M}$ and $I_{R}$ as a function of time in relation to the moment the dog is rewarded whlle walking around

all indices while the anımal was 'walking' were larger than while it was 'standing and eating'. During the 'standing' periods, however, these parameters were smaller than while the anımal was 'standing and eating'. All differences were significant at $P<0.0005$ (Wllcoxon).

As for the time relations between behavioural trigger points and EEG phenomena, it should be noted that the dog often made a last small step to adjust its position when stopping and some preparatory movements before walking away. Hence, by the morphology of the behaviour shown during these transitions, the trigger points are slightly 'blurred', which prevents us from making precise statements about the time relations in these cases. The EEG change, related to the spontaneous transition from standing and eating to walking (Fig. 6B), appears to precede the EMG change by about $0.5 \mathrm{sec}$. The presentation of reward is precisely defined in time. We have therefore analysed the time relation between reward, EEG frequency change and concomitant behavioural change. To this end we have measured the duration of the EEG waves (zero crossings) preceding $\left(\mathrm{T}_{-1}\right)$, during $\left(\mathrm{T}_{0}\right)$, and following $\left(\mathrm{T}_{1}, \mathrm{~T}_{2}\right)$ reward and assessed the differences in wave duration statistically. It was found that the wave during which the reward was given $\left(\mathrm{T}_{0}\right)$ was significantly longer than the preceding wave, probably due to a transient response which disturbs the ongoing activity immediately after the moment of reward (Fig 8B). The EMG burst accompanying the transition from standing to walking contingent upon reward always fell within $T_{0}$. Hence we can conclude that within the resolving power of analysis EMG and hippocampal EEG change significantly simultaneously when triggered by the presentation of reward.

For 15 rewards, given while the dog was walking, the change in hippocampal EEG was analysed, using the same method (Fig. 8C). Again the EEG showed a significant change in zero crossing interval duration between the wave during which the reward was given, and both the preceding wave and the next one.

Supplementary observation. In the course of some experiments the dog would walk more slowly as the experiment proceeded, 
A

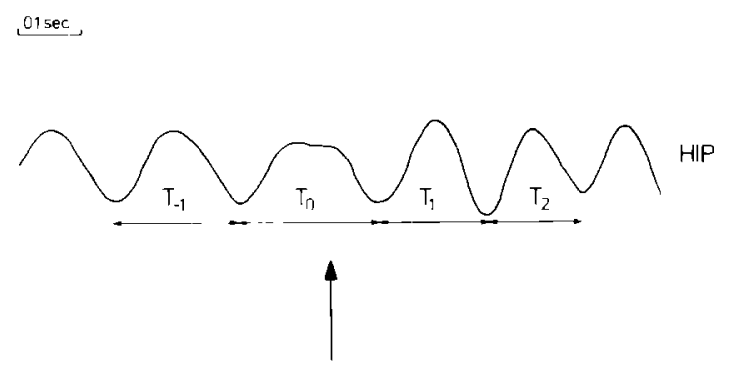

REWARD

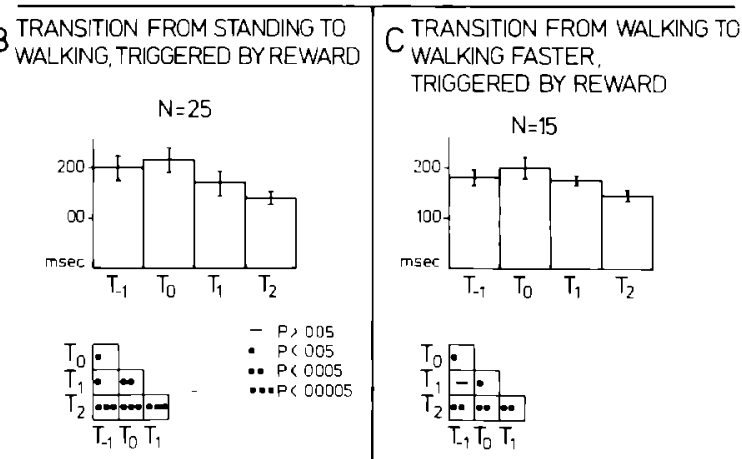

Fig. 8 A single typical registration for reward presented whlle the dog is standing still at a small distance from the food dish. (HIP, hippocampal EEG bandpass filtered between 4 and $8 \mathrm{~Hz}$ ) $\mathrm{B}$ : average duration of the EEG wave during which reward was given $\left(T_{0}\right)$ and that of the wave preceding $\left(T_{-1}\right)$ and the two waves following $T_{0}\left(T_{1}\right.$ and $\left.T_{2}\right)$. The bar through the top of each column indicates the standard error of the mean The degree to which $T_{-1}$, $T_{0}, T_{1}$ and $T_{2}$ differ statistically is shown in the table under the histogram (sign test) C. results of the same analysis for the presentation of reward while the dog is walking.

Fig 9 Upper part for a 'typical head movement', hippocampal EEG (a), EMG of a neck muscle (d), output of the accelerometer on the dog's head (e) and output of the light cell used as movement transducer for the head (f). Next 4 curves average values of the output of the light cell on the head, $I_{P F}, I_{A M}$ and $I_{R}$ as a function of time. The head movements have been averaged using as a trigger the moment at which the movement started Note that this coincides approximately with the end of the previous movement (seen at the left side of the arrow).

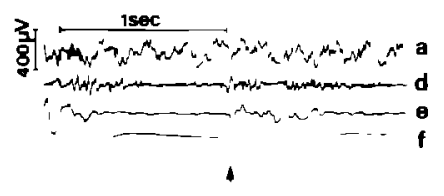

$N=65$
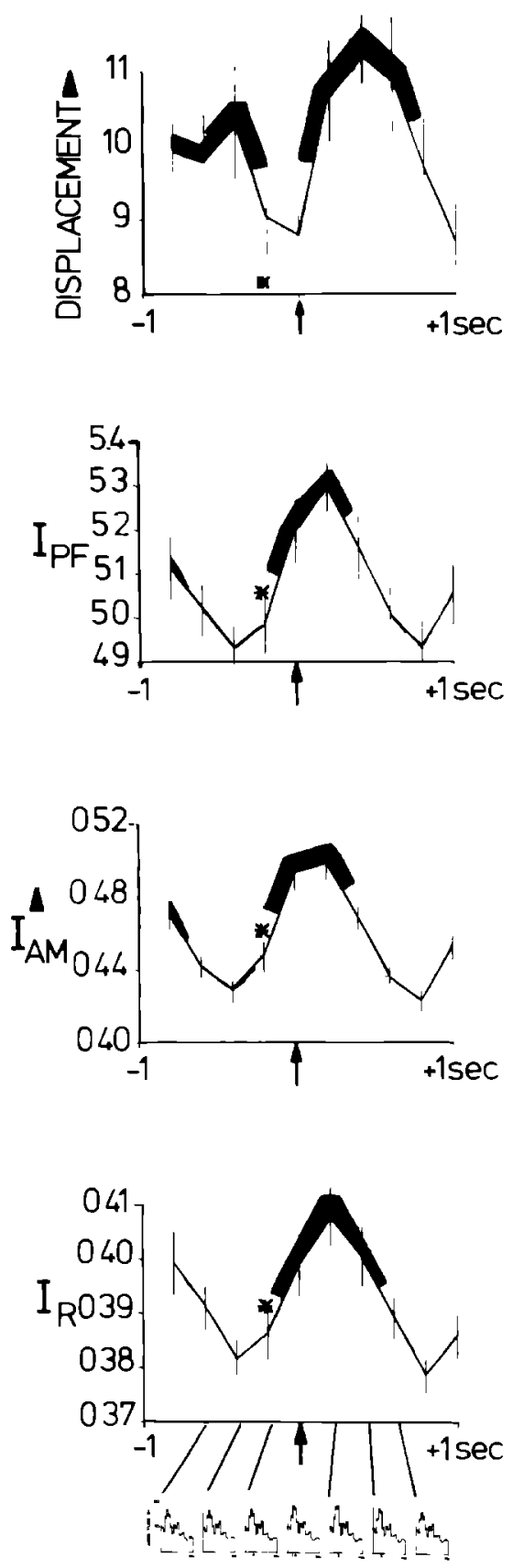
probably due to a gradually increased satiation. In order to test whether this slowing down was correlated with differences in the hippocampal EEG, we compared the periods of walking in the first and second parts of such an experiment as follows: average values of $I_{P F}, I_{A M}$ and $I_{R}$ were computed for 41 independent periods of walkıng in the first half of the experiment (average duration $5.8 \mathrm{sec} /$ period) and for 35 periods of walking in the later part (average duration $6.2 \mathrm{sec} /$ period). The average values of walking speed and of all spectral indices were significantly larger in the first than in the second part: (speed $\cdot P<0.01 ; \mathrm{I}_{\mathrm{PF}} \quad P<0.0005 ; \mathrm{I}_{\mathrm{AM}}: P<$ $0.0005 ; \mathrm{I}_{\mathrm{R}}: P<0.05$, Wilcoxon).

\section{(3) Head movements}

Procedures. This experiment differed from exp. 2 only in that the dog was required to make a series of head movements during its standstill period. This behaviour was shaped during a number of experiments by rewarding small spontaneous head movements and continuously requirmng larger and more intense movements (as judged by eye) for a reward.

Results. The behavioural shaping resulted in series of up to $60 \mathrm{sec}$ duration of large head movements. The dog made about 1 jerk/ sec, moving the head from a neutral position to a position at an angle of about $45^{\circ}$ or more to the body axis. Movements were mostly laterally oriented but sometimes upward. There was some variation in the morphology of these head movements, but at any rate the majority of them were large and vigorous. The occurrence of these head movements was monitored by means of an accelerometer placed on the dog's head and in some cases using the EMG of the neck muscles, as well as by a light cell, placed on the animal's head and lit by a floodlight installed above the place where the animal stood. These indicators were used in conjunction to determine from the curve the sample points at which the head movements started. An analysis of the course of $I_{P F}, I_{A M}, I_{R}$ and the output of the light cell in relation to the start of head move- ments is shown in Fig. 9. It shows that the displacement of the head was correlated with modulations in amplitude, frequency and apparent rhythmicity of the signal

\section{Discussion}

It may be said that, in general, amplitude, peak frequency, and apparent rhythmicity in the theta band of the hippocampal EEG in the dog increase with concurrent behaviour of a transient nature requiring increased muscular activity.

When the behavioural transition was 'cued' by a sensory stımulus it was not possible with the technical facilities available to determine precisely whether the EMG preceded or succeeded the EEG changes; they appeared to coincide in time. However, the EEG appeared to precede the EMG change by about $0.5 \mathrm{sec}$ in the case of a 'spontaneous' transition from standing to walking. The latter observation was also made in rats by Vanderwolf (1969). The main conclusion is that significant correlations between the properties of the hippocampal EEG and gross motor behaviour at a low level of complexity have been clearly established. These correlates hold in all dogs investigated and under varıous experımental circumstances (compare, e g., the results of exp. 1 and 2) and are not sensitive to the position of the hippocampal electrodes we used. This is understandable if one takes into account the contribution of volume conduction to records of theta activity in and around the hippocampal formation (Holsheimer and Feenstra 1977). Of course the present results are not at all contrary to the existence of correlates between hippocampal EEG and sensory events or behaviours at higher levels of complexity (e.g., social behaviour or behaviour during the performance of complex operant tasks). Our results give support to Klemm's (1971) statement that the most straightforward interpretation of the behavioural significance of theta rhythm may be that it is a non-specific correlate of muscle 
activity. They are also in good accordance with the funding of Black and Young (1972) that longer series of theta waves and a higher modal frequency in the theta range occur during pedal pressing than during holding still in dogs. The results of exp. 1 agree with the finding of Black et al. (1970) that dogs, trained under Flaxedil to respond to a conditıoning stımulus (CS) by producing hippocampal theta waves, show more theta response and more skeletal activity upon presentation of the CS in the unparalysed state than do controls.

In general terms our data in dogs support to a certain extent Vanderwolf's hypothesis (1969) that hippocampal RSA is related to 'voluntary' movement. This hypothesis is based mainly on data obtained in rats. We have shown, however, that the RSA displays significant modulations even with head movements while a dog is standing. There is also a clear peak in the theta band while the animal is eating and drinking, which Vanderwolf considers to be 'automatic' and thus not related to RSA in the rat. Even when the dog is just standing still, spectral analysis shows a considerable rhythmicity in the hippocampal EEG. On the basis of these findings we do not deem the term 'voluntary' necessary or desirable in order to describe the behavioural correlate of RSA in the dog.

In our view statements about the 'presence' or 'absence' of RSA can only be of limited value and even then only if the distinction between presence and absence is made on a quantitative basis. The results of our analyses imply that it is desirable to consider the hippocampal EEG as a continuum which shows graded variations in relation to behaviour, as illustrated in Fig. 10. The contention that the hippocampal EEG forms a continuum is supported by direct electrophysiological studies such as by Paiva et al. (1976) who, in a quantitative study, found increases in frequency and amplitude of the hippocampal EEG as the strength of the stimulation of mesodiencephalıc structures increased, up to a certain point. At higher stimulus strengths both am-

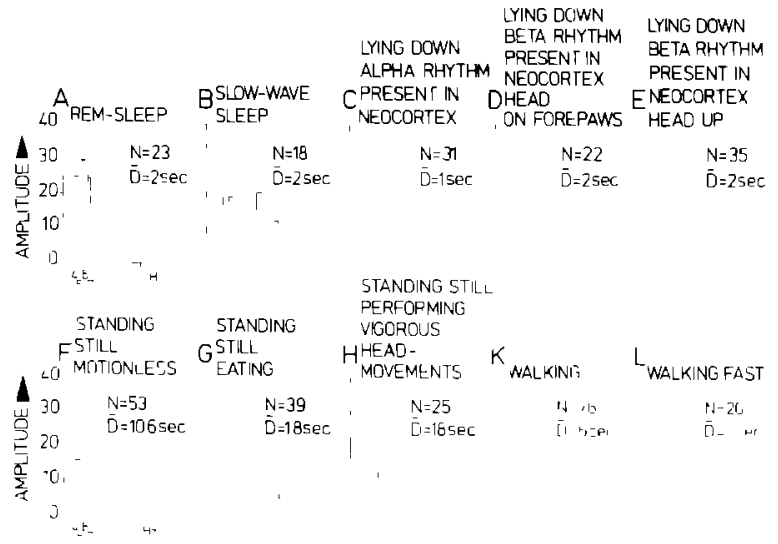

Fig 10 Each histogram in this figure represents the average amplitude spectrum of the hippocampal EEG while the dog is in a certain stationary behavioural state Each spectrum is obtained by averaging ampltude spectra recorded during independent periods of the indicated behaviour. The average duration of each period is given by $\bar{D}$ No periods shorter than $1 \mathrm{sec}$ were averaged The dash through the top of each column indicates the standard error Note that all spectra except $B$ and $C$ show an important frequency component in the theta band and that generally speaking both amplitude and frequency of the activity in the theta band increase as the animal's behavloural state can be considered to be more 'active'

plitude and rhythmicity decreased. According to a computer model for the generation of rhythmical EEG activity, presented elsewhere (Lopes da Silva et al. 1976; Pavva et al. 1976), this desynchronization may indeed be explained by an excessive input level to the septal-hippocampal system responsible for RSA generation. On this basis we can identify in the continuum of the hippocampal EEG the so-called 'modes' reported in the literature: the hippocampal signal can change gradually from large amplitude irregular activity (LIA, Vanderwolf 1971) via rhythmic slow activity (RSA) of increasing frequency and amplitude to smaller amplitude higher frequency RSA, to small amplitude irregular activity (SIA).

Presumably phasic motor acts are represented by a transient burst of activity in brain stem structures that supply input signals to the hippocampus (Segal and Landis 1974). These neural events will be reflected in the 
hippocampal EEG. We assume the hippocampal EEG response to such increases in activity in the brain stem input structures to be a 'ringing response' with low damping. This hypothesis then accounts for the fact that the hippocampal RSA continues after the cessation of movement (Fig. 6C, McFarland 1975). If the hippocampus recelves a series of phasic inputs the ringing EEG responses will overlap. Such will be the case during stepping, each step being a phasic motor act which corresponds to a burst of brain stem activity (Grillner 1975).

Several authors (Kemp and Kaada 1975; Winson 1976) report, however, the occurrence of trains of RSA related to sensory stimulation in cat and rat without concurrent motor behaviour. These findings can be incorporated in the hypothesis of RSA generation outlined above if one accepts that activity in sensory pathways will also converge on limbic midbrain structures and thus will also be reflected in the hippocampal EEG. In most experiments, however (our own included), such sensory effects on the hippocampal EEG will be obscured by EEG phenomena correlated with movement because the animal is either required to move upon sensory stimulation or does so spontaneously (orientation reflex, Grastyán et al. 1959). Dogs and rats seem to be more dependent upon overt motor behaviour to investigate their environment than cats and rabbits. Perhaps this is the reason why the correlate between sensory stımul without concurrent motor behaviour and occurrence of RSA has been reported mainly in rabbit and cat. On one occasion we were able to make a few observations in the dog which were comparable to those reported by Kemp and Kaada (1975) in the cat. A familiar sound used as a CS in other experiments was presented whlle an animal was in slow wave sleep. This caused a train of theta waves to occur together with a neocortical arousal reaction, while no skeletal movement whatsoever could be observed.

In conclusion' the hippocampal EEG is correlated in a non-specific although predictable way with motor behaviour and possibly sensory inputs. Species differences regarding the sensorimotor correlates of the hippocampal EEG may be expressed in terms of, e.g., the frequency band within which RSA occurs, the possible range of RSA amplitude, the signal (RSA)-to-noise ratios under various well defined behavioural circumstances, and the behavioural circumstances under which desynchronization occurs. For example, the desynchronization upon an orientation reaction of the cat, reported by Kemp and Kaada (1975), might be explained by assuming that in the cat the neural activity of the midbrain due to the sensory stimulation, causing the orientation reaction, in combination with the hippocampal input related to the motor behaviour itself, would be sufficient to drive the hippocampus as far as SIA. The SIA reported to occur in a rabbit that runs very fast (Kramis et al. 1975) can be considered in a similar way.

A further problem is that of the postulated correlations between the occurrence of hippocampal RSA and higher processes like learning and information processing (Elazar and Adey 1967; Landfield 1972; Klemm and Douglas 1974). The experimental conditions employed in these studies, however, appear to involve always changing motor behaviours as the learning of a task proceeds. To our knowledge no experiments have been carried out in which careful measurements of overt behaviour showed this to be constant while at the same time the EEG showed changes in relation to the acquisition or performance of the task.

This discussion has purposefully been held at a descriptive-correlative level. Cause-effect relationships cannot be established on the basis of correlative data such as ours, and we deem it useless to add the next theory on the functional significance of the hippocampus, on the basis of theta rhythm studies, to the plethora of theories already available.

In our view there is a great need of comparative and quantitative investigation of brain-behaviour correlates. Data generated in 
this way may enable us to establish a generally valid model which describes the relationship between hippocampal EEG and behaviour in the widest sense across species. Such a model may help in the formulation of theories on the functional importance of the hippocampus which can be experimentally verified.

\section{Summary}

It was shown that rewarding spectral shifts (i.e. increase in amplitude or peak frequency of the hippocampal EEG) causes a solitary dog to show increased motor behaviour. Rewarded spectral shifts concurred with a variety of behavioural transitions.

It was found that statistically significant modulations occur in the spectral properties of the hippocampal EEG correlated with: (1) the transition from walking to standing; (2) the transition from standing while eating to walking away from the food dish; (3) the increase in speed of a walking dog, caused by rewarding the animal; and with (4) each head movement in a learned series of head movements.

Thus behavioural transitions to a more active state are accompanied by an increase of amplitude, frequency and rhythmicity in the theta band of the hippocampal EEG; behavioural transitions to a less active state show the inverse relationship with the hippocampal EEG. A close relationship between modulations of the dog's hippocampal EEG activity and elementary motor acts is stressed. The hypothesis is put forward that the spectral properties of the hippocampal EEG reflect the degree to which a number of motor and sensory structures in the limbic midbrain and brain stem are active.

\section{Résumé}

EEG hippocampique et comportement chez le chien I. Corrélation entre EEG hippocampıque et activité motrice globale

On montre que le fait de fournir une récompense alimentaire à un chien toute les fors que la fréquence et l'amplitude de son EEG hippocampique dépassent un certain niveau (feedback) suscite l'apparition d'une activité motrice variée. Des relations signiflcatives existent entre les caractéristiques spectrales de l'EEG hippocampique et: (1) la transition de 'marcher' à 'se tenir debout immobile', (2) la transition de 'se tenir debout en mangeant' à 'marcher', (3) l'accélération pendant la marche en réponse à une récompense alimentaire et chaque mouvement de la tête dans une sérıe de mouvements conditionnés.

Les transitions vers un comportement plus actif sont accompagnées d'une augmentation de l'amplitude, de la fréquence et de la rythmicité dans la bande des fréquences thêta de l'EEG hippocampique, à des transitions comportementales en direction inverse correspondent des changements inverses du tracé de l'hippocampe. Des relations frappantes existent entre les modulations de l'EEG hippocampique et des mouvements élémentaires. L'hypothèse est formulée, que les caractéristiques spectrales de l'EEG de l'hippocampe reflètent le niveau de l'activité neuronale dans un nombre de structures motrices et sensorielles, appartenant aux circuits limbiques du mésencéphale et du tronc cérébral.

Permission of Pergamon Press to reproduce Fig. 2 is gratefully acknowledged. 


\section{Appendix}

For the frequency analysis of our EEG signals we used a bank of filters with resonance frequencies increasing in steps of $1 \mathrm{~Hz}$. Thus with this system the peak frequency of a signal can be determined with a precision of $1 \mathrm{c} / \mathrm{sec}$. In Fig. $11 \mathrm{~A}$ the output of the filter bank is shown for an input of a $5 \mathrm{~Hz}$ sine wave and in Fig. 11B for a $5.5 \mathrm{~Hz}$ sine wave. In both cases the peak frequency (i.e. the resonance frequency of the filter with the larger amplitude) is $5 \mathrm{~Hz}$. Yet the amplitude in the filters with resonance frequencies at 4 and $6 \mathrm{~Hz}$ indicate that the frequency of the input signal in Fig. 11B was higher than in Fig. 11A. This property was used to construct an interpolation procedure in order to define an index of peak frequency $\left(\mathrm{I}_{\mathrm{PF}}\right)$ that shows a continuous linear relationship with the peak frequency of the input signal. $\mathrm{I}_{\mathrm{PF}}$ was computed according to the following algorithm. The largest amplitude $\left(A_{P}\right)$ of the filters in the band from 2 to $9 \mathrm{~Hz}$ was determined. The resonance frequency of this filter will be called $F_{p}$. In case the output of two filters in the $2-9 \mathrm{~Hz}$ range happened to be equal, $F_{P}$ was defined by the filter with the lower resonance frequency of the two. In order to obtain $I_{P F}$ a fraction $D_{f}$ was added to $F_{P}$. In the computation of $D_{\mathrm{f}}$ the ratio of the amplitudes in the filters flanking the peak filter $\left(A_{p-1}\right.$
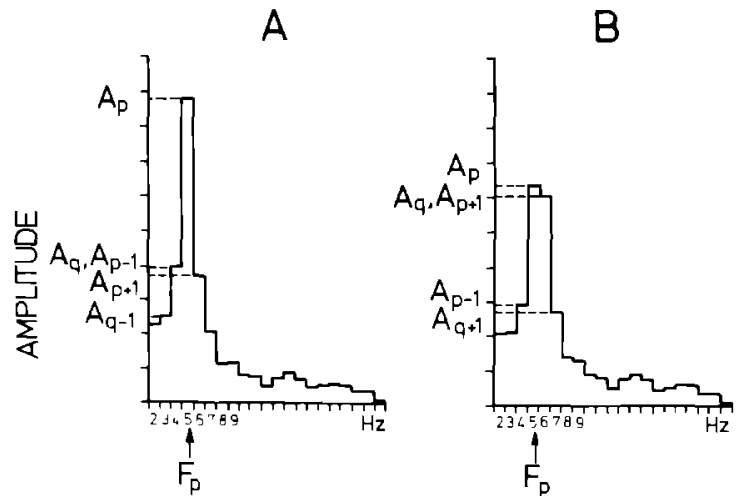

Fig 11. A: spectral analysis of a $5 \mathrm{~Hz}$ sine wave signal. B. spectrum of a $5.5 \mathrm{~Hz}$ sine wave For elucidation see Appendix. and $\left.A_{p+1}\right)$ was used according to.

$D_{\mathrm{f}}=\left[1-\left(\mathrm{A}_{\mathrm{p}-1} / \mathrm{A}_{\mathrm{p}+1}\right)\right] / 2.5$ if $\mathrm{A}_{\mathrm{p}-1} \geqslant \mathrm{~A}_{\mathrm{p}+1}$ and

$D_{f}=\left[\left(A_{p+1} / A_{p-1}\right)-1\right] / 2.5$ if $A_{p-1} \leqslant A_{p+1}$

$D_{f}$ was limited to the values $-0.5 \leqslant D_{f} \leqslant 0.5$.

The filter with the lower resonance frequency was the $2 \mathrm{~Hz}$ filter. Thus, in the boundary case that $F_{P}$ was found to be $2 \mathrm{~Hz}, \mathrm{D}_{\mathrm{f}}$ was defined as:

$D_{\mathrm{f}}=\left[2.5-\left(\mathrm{A}_{2} / \mathrm{A}_{3}\right)\right] / 3.15\left(\mathrm{D}_{\mathrm{f}} \geqslant 0\right)$.

As an index of the amplitude of the rhythmical component of the signal we considered it adequate to use the amplitude in a $3 \mathrm{~Hz}$ wide band, symmetrical around $\mathrm{I}_{\mathrm{PF}}$. To this end we defined $\mathrm{I}_{\mathrm{AM}}$, the amplitude index, as

$\mathrm{I}_{\mathrm{AM}}=\mathrm{A}_{\mathrm{p}}+\mathrm{A}_{\mathrm{q}}+\mathrm{D}_{\mathrm{A} 1}+\mathrm{D}_{\mathrm{A} 2}$

$A_{p}$ is defined as above. $A_{q}$ is the larger value of $A_{p-1}$ and $A_{p+1}$.

If $A_{p-1}=A_{p+1}, A_{q}=A_{p-1}$.

$\mathrm{D}_{\mathrm{A} 1}$ and $\mathrm{D}_{\mathrm{A} 2}$ are obtained by multiplying the amplitude in the filters flanking $p$ and $q$ by a factor which was derived from $D_{f}$. In order to clarify this procedure we will again consider the concrete examples in Fig. 11. Clearly in Fig. 11A $\mathrm{I}_{\mathrm{AM}}$ should approximate $\mathrm{A}_{4}+\mathrm{A}_{5}+$ $A_{6}$ in order to obtain the amplitude in a $3 \mathrm{~Hz}$ wide band symmetrical around the $\mathrm{I}_{\mathrm{PF}}$, which in this case $\approx 5$, while $\mathrm{D}_{\mathrm{f}} \approx 0$. Thus in this case $D_{A 1}=\left|D_{f}\right| \times A_{3}$ and $D_{A 2}=\left(1-\left|D_{f}\right|\right) \times$ $A_{6}$ yields the desired $I_{A M}$.

Fig. 11B represents another extreme in the computation of $\mathrm{I}_{\mathrm{AM}}$. Here, in order to obtain the amplitude in a $3 \mathrm{~Hz}$ wide band symmetrical around the $\mathrm{I}_{\mathrm{PF}} \mathrm{I}_{\mathrm{AM}}$ should approximate $\mathrm{A}_{5}+\mathrm{A}_{6}+\frac{1}{2} \mathrm{~A}_{4}+\frac{1}{2} \mathrm{~A}_{7}$. In this case $\mathrm{I}_{\mathrm{PF}} \approx 5.5$ while $\mathrm{D}_{\mathrm{f}} \approx 0.5$.

Thus $D_{A 1}=D_{f} \times A_{7}$ and $D_{A 2}=\left(1-D_{f}\right) \times A_{4}$ gives the desured result. Interpolation between these two extremes leads to a general definition of $\mathrm{D}_{\mathrm{A} 1}$ and $\mathrm{D}_{\mathrm{A} 2}$ as:
$\left.\begin{array}{l}D_{A 1}=\left|D_{f}\right| \cdot A_{q+1} \\ D_{A 2}=\left(1-\left|D_{f}\right|\right) \cdot A_{p-1}\end{array}\right] F_{q}>F_{p}$ and 
$\left.\begin{array}{l}D_{A 1}=\left|D_{f}\right| \cdot A_{q-1} \\ D_{A 2}=\left(1-\left|D_{f}\right|\right) \cdot A_{p+1}\end{array}\right] F_{q}<F_{p}$

For $\mathrm{I}_{\mathrm{PF}}<3, \mathrm{I}_{\mathrm{AM}}$ was defined as $\mathrm{A}_{2}+\mathrm{A}_{3}+\mathrm{A}_{4}$. Finally we desired an index of how clearly the rhythmical component of the signal emerged from the background. To this end we defined an index of rhythmicity

$I_{R}=I_{A M} / \sum_{n=2}^{n=9} A_{n}$

In order to check the properties of the spectral indices defined in this way, various signals with known properties as to peak frequency, amplitude and bandwidth were analysed.

(1) A series of sinusoldal signals with peak frequency increasing in steps of $0.1 \mathrm{~Hz}$ from 2 to $9 \mathrm{~Hz}$.

(2) The output of a sine wave generator mixed with white noise in various proportions.

(3) Simulated EEG signals with various peak frequencies and bandwidths. These signals were simulated on an analog computer using a model developed in our group (Lopes da Silva et al. 1976).

(4) Bandpass filtered ( $24 \mathrm{~dB} /$ octave) white noise, of which centre frequency, amplitude and bandwidth were systematically varied.

In each of the 4 calibrations $I_{P F}$ showed a consistent monotonous linear increase with the peak frequency of the input signal. Even with the bandpass filtered white noise, which was much more variable and of greater bandwidth than most of the EEG signals analysed, this relationship held. As the amplitude of any of the calibration signals was increased linearly, $\mathrm{I}_{\mathrm{AM}}$ showed a linear increase as well. $I_{H}$ increased monotonously as a function of the signal/noise ratio of the input signal. For each of the indices one representative calibration curve is shown in Fig. 3. These calibrations showed $I_{P F}$ to be markedly independent of the amplitude or bandwidth of the calibration signal and vice versa. Of course some interaction existed between $I_{R}$ and $I_{A M}$ since the defmition of $I_{A M}$ is such that it increases as the bandwidth of the signal becomes wider $\left(I_{R}\right.$ decreases). It must be stressed here that these variables are only indices of frequency, amplitude and rhythmicity, which have no more than a pragmatic value. The indices used in the present study have been defined in a more general way than those published prev1ously (Arnolds and Lopes da Silva 1978). They are indicative in a wider band of frequencies and correspond better to intuitive notions of the frequency, amplitude and rhythmicity of an EEG signal than those used before.

\section{References}

Adrianov, O.C and Meringe, T A Atlas of the Dog's Brain (in Russian) Medgiz, Moscow, 1959, 239 pp

Arnolds, D E A T and Lopes da Silva, F H Computer assisted determination of brain behaviour correlates Physiol Behav, 1977, 19: 377-380

Arnolds, D.E A T , Lopes da Silva, F H., Aitink, W and Kamp, A Motor acts and firıng of reticular neurons correlated with operantly reinforced theta shıfts Brain Res, 1975, 85194

Black, A H and Young, G A. Electrical activity of the hippocampus and cortex in dogs operantly tramed to move and to hold still J. comp. physiol Psychol , 1972, 79 128-141.

Black, A H., Young, G.A and Batenchuk, C Avoldance training of hippocampal theta waves in flaxedilized dogs and its relation to skeletal movement J. comp. physiol. Psychol, 1970, 70 15-24.

Elazar, Z and Adey, W.R. Spectral analysis of low frequency components in the electrical activity of the hippocampus during learning. Electroenceph. clin Neurophysiol , 1967, 23 225-240

Fujıta, Y Two types of depolarizing after-potentials in hippocampal pyramidal cells of rabbits Brain Res., 1975, 94: 435-446

Fujita, Y and Sato, T Intracellular theta rhythm. J Neurophysıol., 1964, 27 1011-1025

Grastyán, E , Lıssák, K, Madarász, I and Donhoffer, $\mathrm{H}$ Hippocampal electrical activity during the development of conditioned reflexes. Electroenceph clin. Neurophysiol , 1959, $11409-430$

Gray, J A Effects of septal driving of the hippocampal theta rhythm on resistance to extinction. Phys1ol. Behav., 1972, 8 481-490

Green, J D and Arduını, A A Hippocampal electrical activity in arousal J. Neurophysıol, 1954, 17 $534-557$. 
Grillner, S Locomotion in vertebrates central mechanısms and reflex interaction. Physıol Rev., 1975, 55. 247-304.

Holsheimer, J. and Feenstra, B W.A. Volume conduction and EEG measurements within the brain: a quantitative approach to the influence of electrical spread on the linear relationship of activity measured at different locations Electroenceph. clin Neurophysiol , 1977, $43 \quad 52-58$

Kamp, A., Lopes da Silva, F.H and Storm van Leeuwen, W. Hippocampal frequency shifts in different behavioural situations Brain Res., 1971, 31- 287-294.

Kemp, I.R. and Kaada, B.R The relatıon of hıppocampal theta activity to arousal, attentive behavlour and somatomotor movements in unrestrained cats. Brain Res., 1975, 95 323-342

Klemm, W.R. EEG and multıple-unit actıvity in lımbic and motor systems during movement and immobility. Physiol Behav., 1971, 7-337-343

Klemm, W.R and Douglas, J H Modulation of hippocampal rhythmic slow activity (theta) by stımulation of other brain areas Physiol Behav, 1974, 12: 205-213.

Kramis, R., Vanderwolf, C.H. and Bland, B H. Two types of hippocampal rhythmical slow activity in both the rabbit and the rat relations to behaviour and effects of atropine, diethyl ether, urethane and pentobarbital Exp Neurol, 1975, 49.5885

Landfıeld, P W., McGaugh, J.L. and Tusa, R J. Theta rhythm: a temporal correlate of memory storage processes in the rat. Science, 1972, $175 \quad 87-89$.

Lim, R.K S, Lin, C N and Moffitt, R A Stereotaxic Atlas of the Dog's Brain. Thomas, Springfıeld, Ill., 1960: 93

Lindsley, D B. and Wilson, C L Brainstem-hypothalamıc systems influencing hippocampal actıvity and behaviour. In $\mathrm{R} \mathrm{L}$ Isaacson and $\mathrm{K} \mathrm{H}$. Pribram (Eds ), The Hippocampus, Vol 2 Plenum Press, New York, 1975-445

Lopes da Silva, FH and Kamp, A. Hıppocampal theta frequency shifts and operant behaviour. Electroenceph. clin. Neurophysiol, 1969, 26
$133-143$

Lopes da Silva, F H, van Rotterdam, A, Barts, P., van Heusden, $E$ and Burr, W Models of neuronal populations the basic mechanisms of rhythmicity. In M A Corner and D F Swaab (Eds,), Perspectives of Brain Research, Progress in Brain Res, Vol. 45. Elsevier, Amsterdam, 1976. 281-308

McFarland, W.L., Teltelbaum, $H$ and Hedges, E.K Relationship between hıppocampal theta activity and running speed in the rat $\mathbf{J}$ comp physiol Psychol , 1975, 88-370-378

Palva, T, Lopes da Silva, F H and Mollevanger, W. Modulating systems of hippocampal EEG Electroenceph clin. Neurophysiol, 1976, $40470^{-}$ 480

Segal, $M$ and Landıs, $S$. Afferents to the hippocampus of the rat studied with the method of retrograde transport of horseradish peroxidase Brain Res, 1974, $78 \quad 1-15$

Storm van Leeuwen, $W$ and Kamp, A Radiotelemetry of EEG and other biological variables in man and dog Proc. roy. Soc Med, 1969, 62. $451-453$

Storm van Leeuwen, W, Kamp, A , Kok, M.L., Quartel, F.W, Lopes da Silva, F H et Tielen, A.M Relations entre les actıvités électriques cérébrales du chien, son comportement et sa direction d'attention Actualı́és neurophysıol, 1967, 7: $167-186$

Vanderwolf, C.H. Hippocampal electrical activity and voluntary movement in the rat Electroenceph. clin Neurophysiol , 1969, 26 407-418

Vanderwolf, C H Limbic-diencephalic mechanisms of voluntary movement. Psychol Rev., 1971, 78: 83-113.

Vanderwolf, C.H, Bland, B H and Whsshaw, I Q Diencephalıc, hippocampal and neocortical mechanisms in voluntary movement In $\mathrm{J} \mathrm{D}$ Maser (Ed.), Efferent Organisation and the Integration of Behaviour Academic Press, London, 1973368

Winson, J Hippocampal theta rhythm II. Depth profiles in the freely moving rabbit Brain Res, 1976, $10371-79$. 